\title{
Przypadkowo wykryte napadowe migotanie przedsionków
}

\author{
Incidentally discovered paroxysmal atrial fibrillation
}

\author{
Magdalena Kumor, Piotr Hoffman
}

Klinika Wad Wrodzonych Serca Instytut Kardiologii w Warszawie

\section{Streszczenie}

W pracy opisano przypadek bezobjawowego, napadowego, wykrytego przypadkowo migotania przedsionków u młodego dorosłego.

Słowa kluczowe: migotanie przedsionków, wielodobowe monitorowanie EKG

Folia Cardiologica 2015; 10, supl. C: $27-30$

\section{Wstęp}

Migotanie przedsionków (AF, atrial fibrillation) jest najczęściej występującą, mogącą mieć negatywne skutki kliniczne arytmią w dorosłej populacji. W połączeniu z nadciśnieniem tętniczym i niewydolnością serca AF zwiększa ryzyko udaru mózgu. Leczenie obejmuje zapobieganie powikłaniom zatorowym w zależności od ryzyka u danego pacjenta oraz kontrolę częstości rytmu lub przywrócenie i utrzymanie rytmu zatokowego.

\section{Opis przypadku}

U 31-letniego informatyka wykonano 7-dniowe monitorowanie elektrokardiogramu (EKG) w ramach programu naukowego testującego nowy tryb urządzenia do stałego telemonitoringu. W 5. dobie badania w godzinach nocnych wystąpiły napady AF trwające około 2 godzin. W 2., 3., 4. i 5. dobie nagrania wystąpiła ekstrasystolia nadkomorowa pojedyncza i złożona (ryc. 1-4), w pozostałych dniach zaburzenia rytmu nie wystąpiły. Częstość rytmu w trakcie napadów wynosiła do 106/min. Wszystkie arytmie były bezobjawowe. W 12-odprowadzeniowym EKG nie było istotnych patologii, nie wystąpiły żadne arytmie, podobnie nie stwierdzono ich w 12-odprowadzeniowym EKG metodą Holtera (ryc. 5).
U pacjenta nie występowały choroby wewnętrzne, wykluczono nadczynność tarczycy, w wywiadzie negował stosowanie używek czy infekcje. Po 2 miesiącach pacjenta poddano kolejnemu 14-dniowemu monitorowaniu, w którym ponownie rejestrowano epizody $\mathrm{AF}$ - w sumie około 2 godzin w 5. i 8. dobie nagrania. Epizody arytmii nadkomorowych były szybsze niż w poprzednich rejestracjach do około 140/min. Pacjent nadal nie wykazywał objawów. Rozpoznano idiopatyczne napadowe AF.

W trakcie diagnostyki wykonano również przezklatkowe badanie echokardiograficzne. Uwidoczniono prawidłowy obraz oraz funkcję serca; jedyną drobną patologią był mały tętniak przegrody międzyprzedsionkowej, bez cech przecieku. Tętniak przegrody przemieszczał się z prawa na lewo; w badaniu przezklatkowym nie rejestrowano przecieku. W trakcie próby wysiłkowej potwierdzono dobrą wydolność wysiłkową, prawidłową reakcję ciśnienia tętniczego, bez arytmii. Według skali $\mathrm{CHA}_{2} \mathrm{Ds}_{2}$-VASc pacjent nie miał wskazań do leczenia przeciwkrzepliwego. Wobec braku objawów nie podejmowano również decyzji o ablacji.

Po roku wykonano badania kontrolne, w których ponownie w 7-dniowej rejestracji, w 2. i 3. dobie, w godzinach wieczornych wystąpiły epizody AF (trwające w sumie ok. 2 h) (ryc. 6, 7) i złożona ekstrasystolia nadkomorowa. W badaniu echokardiograficznym obserwowano stabilny obraz, bez powiększenia przedsionków. Pacjent pozostaje pod obserwacją.

Adres do korespondencji: dr n. med. Magdalena Kumor, Klinika Wad Wrodzonych Serca, Instytut Kardiologii, ul. Alpejska 42, 04-628 Warszawa, e-mail: magdakumor@wp.pl 


\begin{tabular}{|c|c|c|c|c|c|c|c|c|c|c|c|c|c|c|c|}
\hline \multirow[b]{2}{*}{ 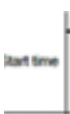 } & \multirow{2}{*}{$\begin{array}{l}\text { Toen } \\
\text { nowe } \\
\text { Bests }\end{array}$} & \multicolumn{2}{|c|}{$\frac{\text { Repe }}{\text { HR }}$} & \multicolumn{6}{|c|}{ 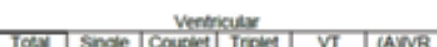 } & \multicolumn{6}{|c|}{$\begin{array}{c}\text { Soprementiouser } \\
\end{array}$} \\
\hline & & 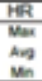 & 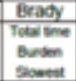 & $\begin{array}{l}\text { TOEN } \\
\text { Deom }\end{array}$ & singe & 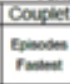 & 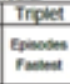 & 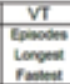 & 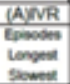 & \begin{tabular}{|c|} 
Total \\
sum \\
\end{tabular} & $\frac{\sin 2 x}{\sec }$ & Cocopodete & 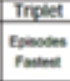 & 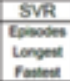 & 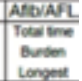 \\
\hline 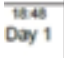 & Sin som & 82 & $:$ & - & - & - & - & : & $\vdots$ & 1 & 1 & - & $\cdot$ & : & $:$ \\
\hline Day 2 & 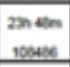 & 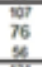 & : & - & - & - & - & : & : & se9 & 282 & $\begin{array}{c}65 \\
112 \operatorname{sen}\end{array}$ & $\begin{array}{c}12 \\
110 \mathrm{egu}\end{array}$ & 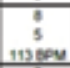 & $\begin{array}{c}\text { काm } \\
0.10 \% \\
g\end{array}$ \\
\hline Day 3 & 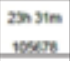 & $\begin{array}{l}n+1 \\
n \\
\end{array}$ & . & - & * & . & . & $:$ & : & 1165 & ses & $\begin{array}{c}81 \\
11802\end{array}$ & $\begin{array}{c}1 \\
\text { 19xes }\end{array}$ & $?^{2}$ & 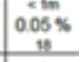 \\
\hline Day 4 & $203 x+60$ & $\begin{array}{l}10 \\
76\end{array}$ & : & - & . & $\cdot$ & - & : & : & 1 & 1 & $\cdot$ & $\cdot$ & : & : \\
\hline Day 5 & 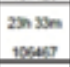 & $\begin{array}{r}721 \\
76 \\
9 \\
\end{array}$ & $\begin{array}{c}<\lim \\
-0.01 \%\end{array}$ & 2 & - & $\begin{array}{c}1 \\
\text { numery }\end{array}$ & - & : & : & $\mid 14910$ & 2462 & $\begin{array}{c}107 \\
\text { 1enen }\end{array}$ & $\begin{array}{c}30 \\
111500\end{array}$ & 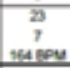 & $\begin{array}{l}\text { 3ish } \\
110 \% \\
1546\end{array}$ \\
\hline Day 6 & $\begin{array}{l}20 \mathrm{sim} \\
1007000\end{array}$ & $\begin{array}{l}\text { nin } \\
n \\
\end{array}$ & $:$ & - & - & " & $\cdot$ & : & : & 3 & 3 & . & . & $\therefore$ & : \\
\hline Day 7 & $\begin{array}{l}2 \pi+0 m \\
11500\end{array}$ & $\begin{array}{l}6 \\
83 \\
4\end{array}$ & : & - & - & $\cdot$ & $\cdot$ & . & : & - & - & - & $\cdot$ & . & - \\
\hline Day 8 & $\begin{array}{l}23 n \times 6 m \\
110009\end{array}$ & $\begin{array}{l}18 \\
80 \\
64 \\
\end{array}$ & : & - & - & . & $\cdot$ & : & : & 5 & 5 & - & . & : & : \\
\hline 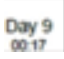 & $\begin{array}{c}\text { on } 11 \mathrm{~m} \\
\mathrm{ang}\end{array}$ & \begin{tabular}{l}
$\mathbf{n}$ \\
81 \\
\hdashline
\end{tabular} & : & - & - & - & . & * & . & - & $\cdot$ & . & - & : & : \\
\hline
\end{tabular}

Rycina 1. Dobowy rozkład arytmii w monitorowaniu 7-dniowym

A

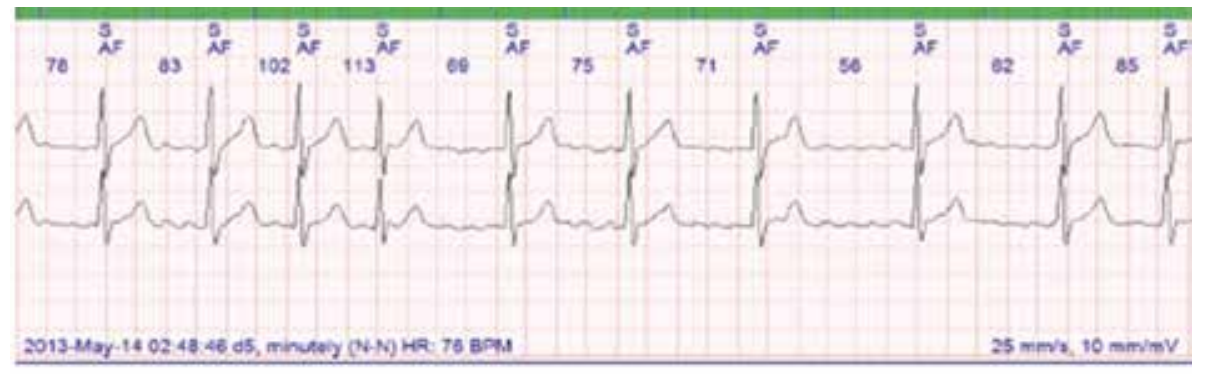

B

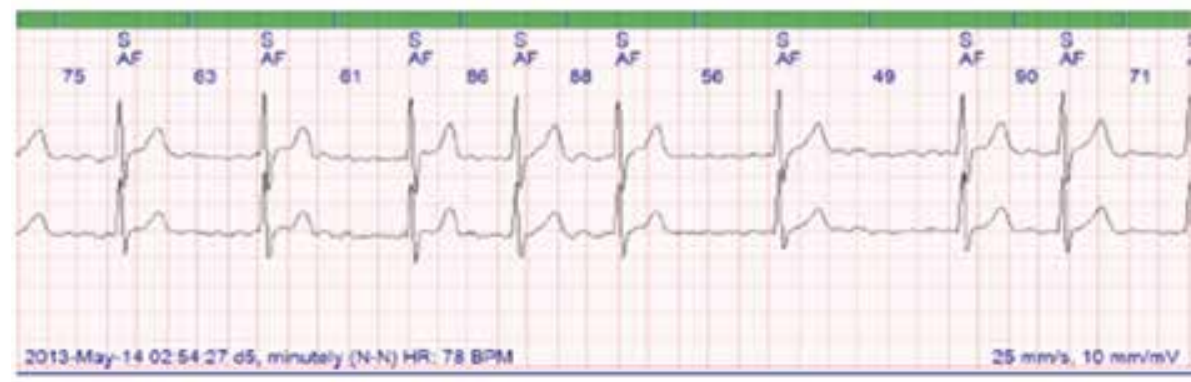

C

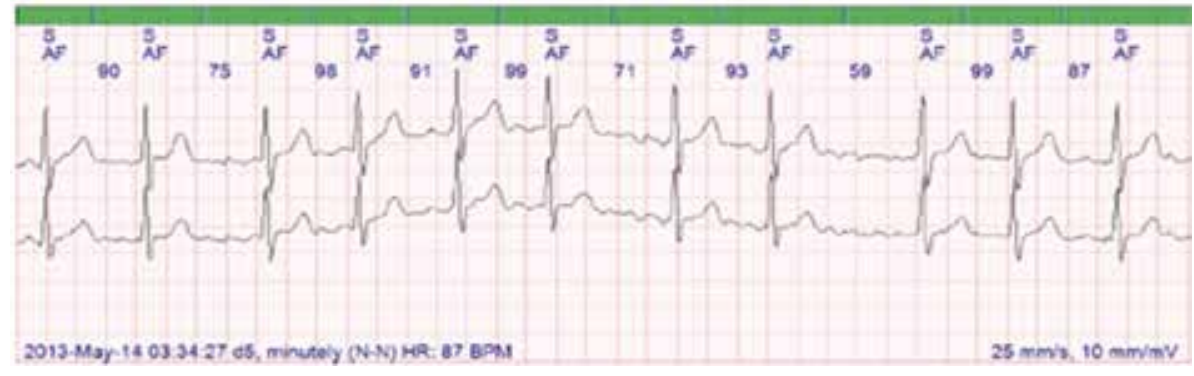

Rycina 2A-C. Migotanie przedsionków rejestrowane w godzinach nocnych 


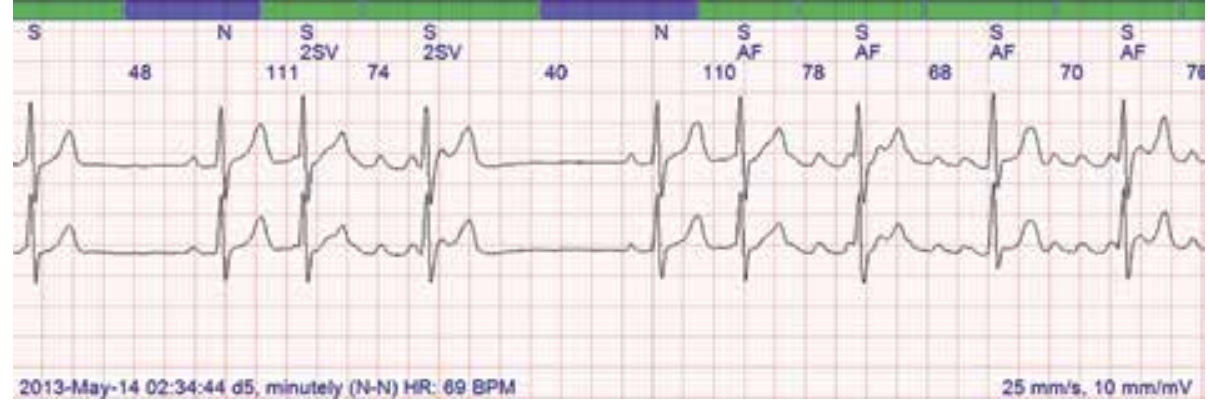

Rycina 3. Początek arytmii

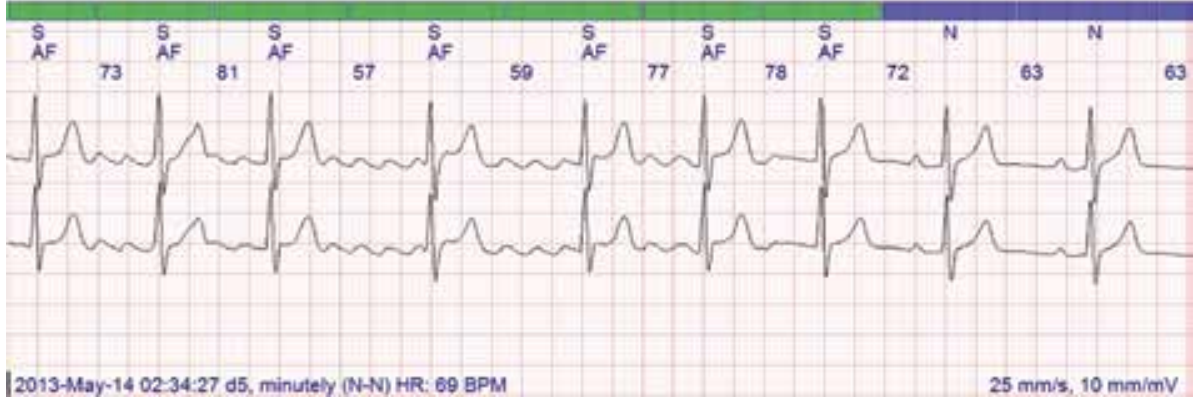

Rycina 4. Koniec migotania przedsionków

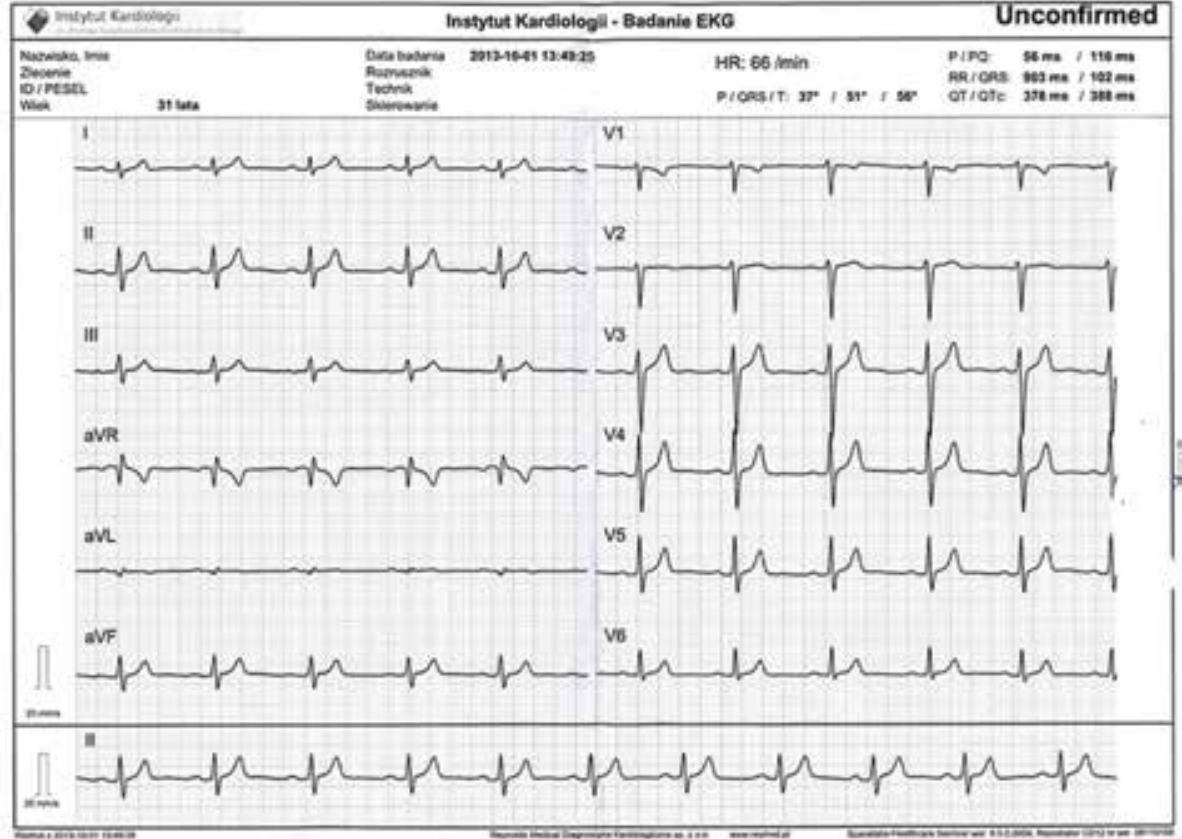

Rycina 5. Zapis 12-odprowadzeniowego elektrokardiogramu

\section{Omówienie}

W populacji osób poniżej 40. roku życia AF jest dość rzadkie (<0,1\%); jego częstość wzrasta do około $20 \%$ po 80. roku życia. Postępowanie w objawowym AF jest dość dobrze udokumentowane w piśmiennictwie, choć nie wykazano przewagi strategii utrzymania rytmu zatokowego na kontrolą częstości rytmu w zmniejszeniu śmiertelności. Leczenie napadowego AF to z jednej strony zapobieganie powikłaniom udarowym, a z drugiej - leczenie objawów oraz zapobieganie progresji choroby prowadzącej do remodelingu przedsionków i utrwalenia arytmii [1]. Czynniki ryzyka wystąpienia AF to ogólnie uznane: niewydolność serca, choroby strukturalne serca (w tym wady serca), nadciśnienie 


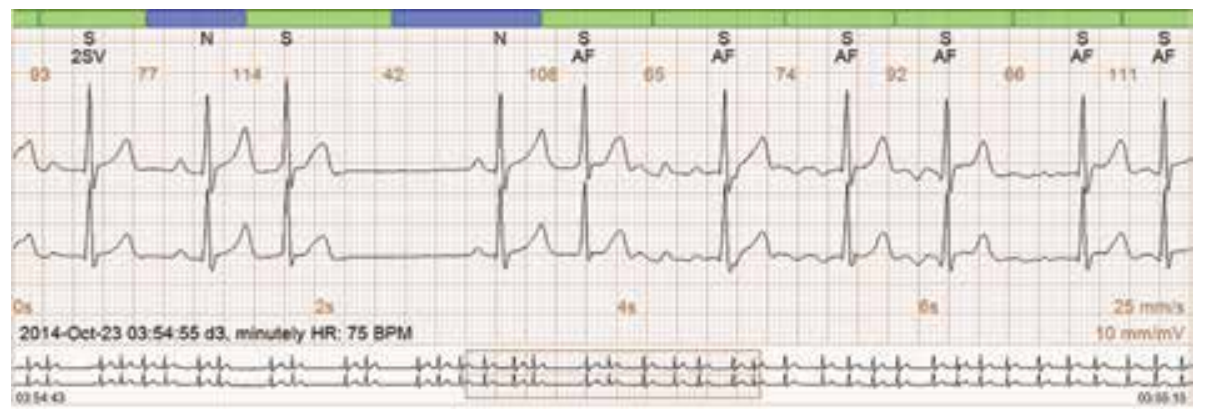

Rycina 6. Początek migotania przedsionków po rocznej obserwacji

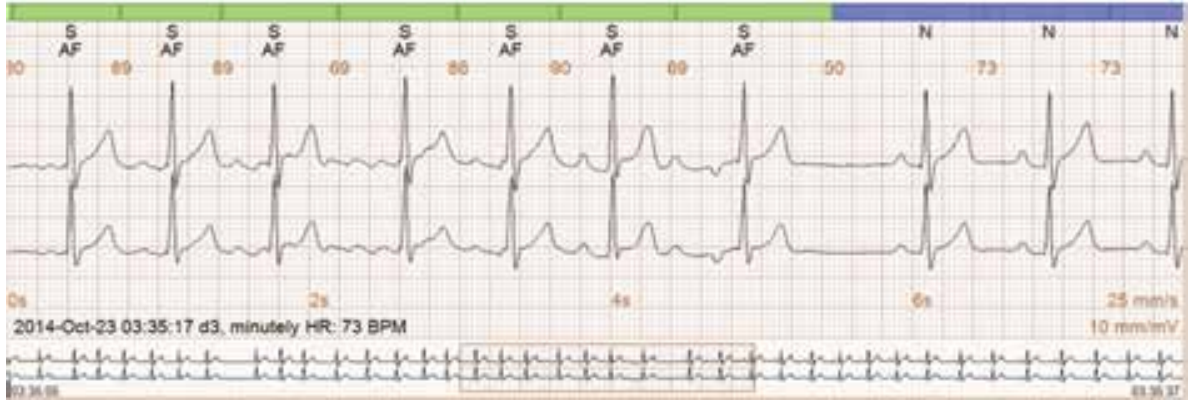

Rycina 7. Koniec migotania przedsionków

tętnicze, wiek, predyspozycja genetyczna, nadczynność tarczycy. Czynniki ryzyka izolowanego AF występującego poniżej 60. roku życia są słabiej udokumentowane. Rozważano wpływ używek (alkoholu, marihuany, palenia tytoniu), masy ciała, cech osobowości, aktywności fizycznej [2-5]. Żadnego z powyższych czynników ryzyka nie stwierdzono u opisywanego pacjenta. W opisywanym przypadku trudno znaleźć przyczynę arytmii; słabe powiązanie może wskazywać na tętniak przegrody międzyprzedsionkowej.

Nie ma danych w zaleceniach dotyczących młodych pacjentów bez objawów wskazujących, że farmakologiczne leczenie AF metodami inwazyjnymi wpływa na śmiertelność, także ryzyko udaru nie zmienia się w zależności od przyjętej strategii leczenia. Młodzi pacjenci bez objawów nie byli objęci badaniami klinicznymi [6].

Wobec braku objawów klinicznych, uznając, że ryzyko okołozabiegowe przewyższa spodziewane korzyści, nie kierowano pacjenta na ablację. Pozostaje on pod obserwacją; w momencie pojawienia się objawów zostanie skierowany na zabieg ablacji.

\section{Konflikt interesów}

Autorzy deklarują brak konfliktu interesów.

\section{Abstract}

The case report of paroxysmal, silent, incidentally diagnosed atrial fibrillation in young adult.

Słowa kluczowe: paroxysmal atrial fibrillation, long term ECG monitoring

Folia Cardiologica 2015; 10, supl. C: 27-30

\section{Piśmiennictwo}

1. Van Wagoner D. Electrophysiological remodeling in human atrial fibrillation. Pacing Clin. Electrophysiol. 2003; 26 (7 Pt 2): 1572-1575.

2. Nabauer M., Gerth A., Limbourg T. i wsp. The Registry of the German Competence NETwork on Atrial Fibrillation: patient characteristics and initial management. Europace 2009; 11: 423-434.

3. Weijs B., Pisters R., Nieuwlaat R. i wsp. Idiopathic atrial fibrillation revisited in a large longitudinal clinical cohort. Europace 2012; 14: 184-190.
4. Korantzopoulos P., Liu T., Papaioannides D., Li G., Goudevenos J.A. Atrial fibrillation and marijuana smoking. Int. J. Clin. Pract. 2008; 62: 308-313.

5. Ofman P., Khawaja 0., Rahilly-Tierney C.R. i wsp. Regular physical activity and risk of atrial fibrillation: a systematic review and metaanalysis. Circ. Arrhythm. Electrophysiol. 2013; 6: 252-256.

6. Wasmer K., Breithardt G., Eckardt L. The young patient with asymptomatic atrial fibrillation: what is the evidence to leave the arrhythmia untreated? Eur. Heart J. 2014; 35: 1439-1447. 